\title{
PNEUMATOSIS CYSTOIDES INTESTINALIS - A REVIEW
}

\author{
René Vobořil \\ Charles University in Prague, Faculty of Medicine in Hradec Králové: Department of Surgery
}

\begin{abstract}
Summary: Pneumatosis cystoides intestinalis is a rare disease characterized by presence of multilocular cysts in the gastrointestinal wall. Idiopatic and secondary forms of the disease can be distinguished. There are presented several theories explaining pneumatogenesis in this article. The specific and non-specific symptoms are described. Attention is drawn to the pneumoperitoneum without signs of peritoneal irritation, what is a typical complication of this disease. The suspition of pneumatosis cystoides intestinalis may be based on plain abdominal X-ray, and is usually confirmed by computer tomography or magnetic resonance imaging. The therapy can be conservative or surgical. In conclusion, although pneumatosis cystoides intestinalis is a rare disease, it may represent a problem in differential diagnosis of abdominal pain.
\end{abstract}

Key words: Pneumatosis cystoides intestinalis; Pneumoperitoneum; Cysts

\section{Introduction}

Pneumatosis cystoides intestinalis (PCI) is not too a frequent disease characterized by multilocular gas cysts localized in the wall of the alimentary tract. The rupture of the cysts leads to pneumoperitoneum in the absence of the signs of peritoneal irritation, which is considered to be pathognomic for this disease. Purpose of this paper is to draw attention to pneumatosis cystoides intestinalis - a rare entity, but an important one for clinical practice, futher to show recent view on this problem and notice the supposed etiology, clinical presentation and treatment.

\section{Etiology and pathogenesis}

According to Kreiss et al. (33) PCI can be clasified either the idiopathic with unknown etiology $(15 \%)$ or the secondary one $(85 \%)$, in which the mechanism of cysts origin has been explained. Several theories elucidating the pathogenesis of this disorder have been proposed.

\section{Mechanical theory}

The mechanical theory explains the pathogenesis of pneumatosis by physical factors. Two pathogenetic mechanisms have been proposed: air leakage from lung interstitium to mediastinum, retroperitoneum, mesenterium and intestinal wall, and leakage of intraluminal gas through gaps in intestinal mucosa. The first mechanism has been proposed in patients with chronic obstructive lung disease or with other illness of the respiratory system (48). A rise in intraalveolar pressure leads to alveolar rupture and leakage of air into lung interstitium. Air from lung interstitium is thought to dissipate via mediastinum, retroperitoneum and mesenterium into the gut wall (37). The second mechanism is represented by increase of intraluminal bowel pressure, which in connection with damage of the mucosa leads to intramural penetration of gas. This can explain the fact that PCI is often present in patients who have gastrointestinal disease - peptic ulcer disease, Crohn's disease $(24,48)$ or necrotizing enterocolitis $(11,27,32)$. Necrotizing enterocolitis with PCI has been induced experimentally by arterial and lymphatic ligation (46). Some others (41) explain PCI as a consequence of reparation after bowel ischemia.

\section{Bacterial theory}

Bacterial theory explains the pathogenesis of PCI by bacterial infection. This infection either damages the intestinal wall with subsequent intramural penetration of gas, or produces gas, which then penetrates into the gut wall. Gas can also enter the lymphatic vessels and cause their dilatation. This theory is supported by experiments in rats, where PCI was induced by Clostridium perfringens (52). The microorganisms playing role in origin of PCI are Clostridium difficile, cytomegalovirus (44) or Clostridium perfringens (7).

\section{Immunopathological inflammatory reaction}

Based on observation by Holl et al. (22) and their demonstration of histiocytes and foreign-body giant cells present in the afflicted part of the bowel, immunopathological inflammatory reaction has been proposed as a cause of PCI. The presence of monocytes and similar mononuclear cells has been confirmed by Gagliardi et al. (19). 


\section{PCI after bone marrow transplantation}

PCI has been also described after bone marrow transplantation (6). The effect of long term steroid use, infection, immunosuppression, graft-versus-host disease are thought to cause disorder in these cases (36).

\section{PCI in connective tissue disease}

The increase of PCI incidence in patients with a connective tissue disease has been observed $(2,10,21,30,34)$. PCI in these patients is probably caused by damage of the gut wall primary by this illness or secondary owing to the ischemia after failure of vessels supply.

\section{Failure of activity hydrogen metabolizing bacteria}

PCI is characterized by high level of breath hydrogen, patients with PCI excrete more hydrogen than others. Clinical features of PCI may be in consequence of abnormal hydrogen metabolism. In normal subjects hydrogen is consumed by methanogenic and sulfatereducing bacteria. The activity of these bacteria is missing in patients with PCI. This leads to the intraluminal gas accumulation, to an increase of intraluminal pressure and thus to intramural gas penetration $(12,13)$. The mechanism just described can explain cysts origin. According to Levitt et al. (35) the hydrogen hyperproduction is only the initial reason for cysts origin. Their futher persistence is caused by nitrogen and oxygen, which diffuse from blood (35).

\section{Clinical presentation}

\section{Presence and character of symptoms}

The character of symptoms is dependent on the localization of PCI and on presence or non-presence of basic disease. Symptoms, which can appear, are either non-specific or specific ones. Abdominal distension (29,34), diarrhoea $(10,19,29,39)$, abdominal pain $(10,39)$, constipation $(19,39)$, mucus discharge $(19,39)$, hematemesis $(34)$, rectal bleeding (19,39), meteorism (14) and weight loss (10) belong to non-specific symptoms. Among the specific symptoms there belong cysts, which can be source of origin of invagination (1) or volvulus (5) and can cause interception of motility and the mechanical obstruction (26). It is especially necessary to draw attention to cysts ruptures, which lead to pneumatosis specific complication - pneumoperitoneum without alarming signs of peritoneal irritation $(16,23,26,28,31)$. Pneumoretroperitoneum develops by cyst rupture in retroperitoneal part of bowel. The mentions of pneumoretroperitoneum are repeated in the literature $(28,31,37)$. During these complications patients usually complain of non-specific abdominal disorder. Pneumoperitoneum diagnosed on abdomen X-ray examination is followed by laparotomy when perforation of alimentary tract in common location is not found (3). Clinical course of PCI may be benign, however also alarming and requiring surgical intervention (8).

\section{Localization of damage}

Occurence of PCI was described in right colon (21), further in transversum (6) or left colon $(18,19)$. Moote et al. (40) conclude that sigma has predisposition to the occurence of the illness. The cysts in sigmoid localization cause sigmoid colon redundancy by affecting sigmoid mesentery. Rectum is usually spared (49). There is also described the incidence of PCI in other parts of alimentary tract - small intestine $(35,42)$, stomach $(4,6)$. Small intestine infliction can be connected with malabsorption (39) or with coeliac disease (45), the gastric infliction is unusual (15).

\section{Age and sex}

Beyond infancy the PCI is rare (44). In Bertram's et al. (7) opinion the period with the most frequent incidence of PCI is age between 30 and 50 years, a clear sexual predominance doesn't exist.

\section{Diagnostics}

When PCI suspected the first examination is plain radiography of abdomen (26,51). There are seen the cysts in the bowel wall or free air under diaphragm in the case of their rupture and pneumoperitoneum appearance. The next diagnostic method can be represented by barium enema examination $(7,40)$. Further it is possible to complete other investigations, which are more sensitive but also more expensive. Sonography that is able to diagnose the cysts is according to some authors $(20,51)$ suitable method, too. Computer tomography remains the most successful technique for initial diagnosis and subsequent follow up (17,51). Its disadvantage is high radiation stress and financial severity. It is also possible to use magnetic resonance in PCI diagnostics (43). Furthermore, but less frequently, PCI can be diagnosed by other ways, as diagnostic laparoscopy (38), endoscopical methods $(15,18,34,51)$ and $\mathrm{H}_{2}$ test, which enables to detect higher breath level of hydrogen by patients with PCI (12).

\section{Therapy}

In asymptomatic patients with PCI no special therapy is recommended $(9,18)$. If a basic disease is present, then it is necessary to treat it and secondary cysts regression is usually observed. PCI therapy could be conservative or surgical one.

\section{Conservative therapy}

Conservative therapy can be causal or symptomatical. The causal therapy includes ways suppressing supposed etiological mechanisms. Inhibition principles of these mechanisms consist either in restriction of intestinal gas producting microflora - administration of antibiotics, es- 
pecially metronidazol $(7,29,31,47)$, or in inhibition of process leading to the hydrogen hyperproduction - hyperbaric oxygen inhalation $(7,31,42)$. In another way of treatment there is possible to include a diet low in flatulence-producing carbohydrates (14), parenteral nutrition $(29,31)$, endoscopical puncture and cysts sclerotherapy (25), therapy with long-acting somatostatin analogue (30). Symptomatical therapy suppresses single symptoms (19) - as pain, constipation, diarrhoea.

\section{Surgical therapy}

Patients with pneumoperitoneum without signs of peritoneal irritation when diagnosis of PCI is known are not necessary to operate $(23,44)$, it is sufficient enough to observe them (23). Surgery is indicated only in fulminant cases (3). The most frequent surgical solution is gut resection (7) or limited colectomy (50).

\section{Conclusion}

To conclude: pneumatosis cystoides intestinalis is a rare entity with uncomplicated recognition by modern diagnostic methods. The practical importance of this paper is to inform about this problem and thus enable to avoid the laparotomy in patients suffering from PCI with pneumoperitoneum without signs of peritoneal irritation.

\section{References}

1. Ahrar K, Watkins GE, Gardiner G. Colocolic intussusception caused by pneumatosis cystoides coli. Abdom Imaging 1997;22(4):392-4.

2. Alcocer-Gouyonnet F, Chan-Nunez C, Hernandez J, Guzman J, GamboaDominguez A. Acute abdomen and lupus enteritis: thrombocytopenia and pneumatosis intestinalis as indicators for surgery. Am Surg 2000;66(2):193-5.

3. Andresen SJ, Gronneberg KG, Oppedal T. Pneumatosis cystoides intestinalis. Tidsskr Nor Laegeforen 1999;119(12):1756-7.

4. Antela CC, Antela LA, Masa VL et al. Intestinal and gastric cystoid pneumatosis associated with duodenal stenosis. Rev Esp Enferm Dig 1990; 77(5):361-4.

5. Azimuddin K, Bourne R. Pneumatosis cystoides intestinalis in a case of sigmoid volvulus. Br J Hosp Med 1997;57(9):468-9.

6. Bates FT, Gurney JW, Goodman LR, Santamaria JJ, Hansen RM, Ash RC. Pneumatosis intestinalis in bone-marrow transplantation patients: diagnosis on routine chest radiographs. Am J Roentgenol 1989;152(5):991-4.

7. Bertram P, Treutner KH, Winkeltau G, Booss HJ, Staatz G, Schumpelick V. Pneumatosis cystoides intestini. Langenbecks Arch Chir 1993;378(4):249-54.

8. Boerner RM, Fried DB, Warshauer DM, Isaacs K. Pneumatosis intestinalis. Two case reports and a retrospective review of the literature from 1985 to 1995. Dig Dis Sci 1996; 41(11):2272-85.

9. Brewaeys P, Ysebaert D, Hubens G, Vaneerdeweg W, Eyskens E. Pneumatosis cystoides intestinalis. Conservative approach in non surgical pneumoperitoneum: a case report and literature review. Acta Chir Belg 1995;95(4 Suppl):195-8.

10. Cabrera GE, Scopelitis E, Cuellar ML, Silveira LH, Mena H, Espinoza LR Pneumatosis cystoides intestinalis in systemic lupus erythematosus with intestinal vasculitis: treatment with high dose prednisone. Clin Rheumatol 1994;13(2):312-6

11. Chabot VH, Slovis TL, Cullen M. Recurrent pneumatosis intestinalis in young infants. Pediatr Radiol 1992;22(2):120-2.

12. Christl SU, Gibson GR, Murgatroyd PR, Scheppach W, Cummings JH. Impaired hydrogen metabolism in pneumatosis cystoides intestinalis. Gastroenterology 1993;104(2):392-7

13. Christl SU, Scheppach W, Kasper H. Hydrogen metabolism in the large intestine-physiology and clinical implications. Z Gastroenterol 1995;33(7):408-13.

14. Christl SU, Scheppach W, Kasper H. Pneumatosis cystoides intestinalis. Dtsch Med Wochenschr 1996:121(7):195-9.

15. Cordum NR, Dixon A, Campbell DR. Gastroduodenal pneumatosis: endoscopic and histological findings. Am J Gastroenterol 1997;92(4):692-5.
16. Daly BD, Guthrie JA, Couse NF.Pneumoperitoneum without peritonitis. Postgrad Med J 1991;67(793):999-1003.

17. Dorenberg E. Diagnostic imaging in intestinal pneumatosis. Tidsskr Nor Laegeforen 1999;119(22):3266-8.

18. Estermann F, Denis B, Gaucher P, Regent D, Sondag D. Pneumatosis cystoides of the colon: knowing how to recognize it. Apropos of 8 cases. Ann Gastroenterol Hepatol Paris 1994;30(4):151-5.

19. Gagliardi G, Thompson IW, Hershman MJ, Forbes A, Hawley PR, Talbot IC. Pneumatosis coli: a proposed pathogenesis based on study of 25 cases and review of the literature. Int J Colorectal Dis 1996;11(3):111-8.

20. Goske MJ, Goldblum JR, Applegate KE, Mitchell CS, Bardo D. The "circle sign": a new sonographic sign of pneumatosis intestinalis - clinical, pathologic and experimental findings. Pediatr Radiol 1999;29(7):530-5.

21. Hiraishi T, Tokuda M, Mitsunaka H, Dobashi H, Takahara J. Asymptomatic pneumatosis cystoides intestinalis in a patient with systemic lupus erythematosus. Ryumachi 1999;39(3):580-5.

22. Holl K, Nolte H, Zornig C, Schroder S. Pneumatosis intestinalis - histology, immunocytochemistry and new theory of morphogenesis. Pathologe 1993;14(4):199-204.

23. Hoover EL, Cole GD, Mitchell LS, Adams CZ Jr, Hassett J. Avoiding laparotomy in nonsurgical pneumoperitoneum. Am J Surg 1992;164(2):99-103.

24. Iitsuka T, Kobayashi M, Izumi Y, Koyama A. Pneumatosis cystoides intestinalis following steroid treatment in a nephrotic syndrome patient: report of a case. Nippon Jinzo Gakkai Shi 1993;35(3):293-7.

25. Johansson K, Lindstrom E. Treatment of obstructive pneumatosis coli with endoscopic sclerotherapy: report of a case. Dis Colon Rectum 1991;34(1):94-6.

26. Keene JG. Pneumatosis cystoides intestinalis and intramural intestinal gas. J Emerg Med 1989;7(6):645-650

27. Keller KM, Schmidt H, Wirth S, Queisser-Luft A, Schumacher R. Differences in the clinical and radiologic patterns of rotavirus and non-rotavirus necrotizing enterocolitis. Pediatr Infect Dis J 1991;10(10):734-8.

28. Kirchner J, Lorenz M, Heyd R, Gute P, Jacobi V. Pneumoperitoneum and pneumoretroperitoneum without perforation. Zentralbl Chir 1996;121(10):861-5.

29. Kirchner J, Seipelt G, Heyd R, Dietrich CF, Jacobi V. Disseminated pneumoperitoneum during the therapy of lymphoma with methotrexate and cytosine arabinoside. Dtsch Med Wochenschr 1996;121(42):1288-91.

30. Kobayashi T, Kobayashi M, Naka M, Nakajima K, Momose A, Toi M. Response to octreotide of intestinal pseudoobstruction and pneumatosis cystoides intestinalis associated with progressive systemic sclerosis. Intern Med 1993;32(7):6079.

31. Kopp AF, Gronewaller E, Laniado M. Pneumatosis cystoides intestinalis with pneumoperitoneum and pneumoretroperitoneum following chemotherapy. Abdom Imaging 1997;22(4):395-7.

32. Kosloske AM, Musemeche CA, Ball WS Jr, Ablin DS, Bhattacharyya N. Necrotizing enterocolitis: value of radiographic findings to predict outcome. Am J Roentgenol 1988;151(4):771-4

33. Kreiss C, Forohar F, Smithline AE, Brandt LJ. Pneumatosis intestinalis complicating C. difficile pseudomembranous colitis. Am J Gastroentero 1999;94(9):2560-1.

34. Lanspa SJ, Liu MW, Jenkins HJ Jr. Giant bulla in pneumatosis cystoides intestinalis. J Clin Gatroenterol 1988;10(4):437-40.

35. Levitt MD, Olsson S. Pneumatosis cystoides intestinalis and high breath $\mathrm{H}_{2}$ excretion: insights into the role of $\mathrm{H}_{2}$ in this condition. Gastroenterology 1995;108(5):1560-5

36. Lipton J, Patterson B, Mustard R et al. Pneumatosis intestinalis with free air mimicking intestinal perforation in a bone marrow transplant patient. Bone Marrow Transplant 1994;14(2):323-6.

37. Mack P. Pneumoretroperitoneum associated with pneumatosis cystoides intestinalis. Ann Acad Med Singapore 1988;17(4):600-2.

38. Mehta SN, Friedman G, Fried GM, Mayrand S. Pneumatosis cystoides intestinalis: laparoscopic features. Am J Gastroenterol 1996;91(12):2610-2.

39. Micklefield GH, Kuntz HD, May B. Pneumatosis cystoides intestinalis: case reports and review of the literature. Mater Med Pol 1990;22(2):70-2.

40. Moote DJ, Fried LA, LeBrun GP, Fraser DB. Pneumatosis coli: is there a relationship with sigmoid colon redundancy? Gastrointest Radiol 1989;14(1):79-82.

41. Morali GA, Braverman DZ, Zimran A, Gottschalk S, Dollberg M. Pneumatosis cystoides intestinalis of the splenic flexure. Harefuah 1990;119(12):428-30.

42. Paw HG, Reed PN. Pneumatosis cystoides intestinalis confined to the small intestine treated with hyperbaric oxygen. Undersea Hyperb Med 1996;23(2):115-7.

43. Rabushka LS, Kuhlman JE. Pneumatosis intestinalis. Appearance on MR examination. Clin Imaging 1994;18(4):258-61.

44. Reynolds HL Jr, Gauderer MW, Hrabovsky EE, Shurin SB. Pneumatosis cystoides intestinalis in children beyond the first year of life: manifestations and management. J Pediatr Surg 1991;26(12):1376-80.

45. Sackier JM, Smith EJ, Wood CB. Cystic pneumatosis in coeliac disease. Gut 1988; 29(6):852-5. 
46. Sibbons P, Spitz L, van Velzen D. The role of lymphatics in the pathogenesis of pneumatosis in experimental bowel ischemia. J Pediatr Surg 1992;27(3):339-43.

47. Tak PP, Van Duinen CM, Bun P et al. Pneumatosis cystoides intestinalis in intestinal pseudoobstruction. Resolution after therapy with metronidazole. Dig Dis Sci 1992;37(6):949-54.

48. Tompolska KA, Wulff C. Air cysts in the small intestine. Ugeskr Laeger 1993;155(35):2713-4

49. Trittmacher S, Felsenberg D, Bachmann G. Diagnosis of pneumatosis intestinalis coli in CT. Radiologe 1992;32(10):523-4.

50. Woodward A, Lai L, Burgess B, Beynon J, Carr ND. A case of pneumatosis col managed by restorative proctectomy and ileal pouch - anal anastomosis. Int J Colorectal Dis 1995;10(3):181-2.

51. Xavier JL, Boscagi G, Claudel N et al. Pneumatosis cystoides intestinalis Apropos of a case. Ann Radiol Paris 1991;34(6-7):401-6.

52. Yale CE, Balish E. The natural course of Clostridium perfringens - induced pneumatosis cystoides intestinalis. J Med 1992;23(34):279-288.

Submitted September 2001

Accepted November 2001.

MUDr. René Vobořil,

Rusek 106,

50003 Hradec Králové,

Czech Republic.

e-mail: rene.voboril@seznam.cz 